\title{
Crystallographic Properties of a Series of Synthetic Hydroxyapatites
}

\author{
Toshiro SAKAE, J. E. DAVIES*, R. M. FRANK** and \\ Noriyuki NAGAI***
}

(Received 10 March and accepted 4 April 1989)

Key words: hydroxyapatite, X-ray diffraction, a-axis length, crystallinity

\begin{abstract}
The crystallographic properties of hydroxyapatites synthesized at temperatures of $200^{\circ} \mathrm{C}, 500^{\circ} \mathrm{C}, 900^{\circ} \mathrm{C}$ and $1250^{\circ} \mathrm{C}$, designated HAP200, HAP500, HAP900 and HAP1250, respectively, were studied using X-ray powder diffraction. Values of a-axis length for the hydroxyapatites ranged from $9.406 \AA$ to $9.416 \AA$, which were smaller than the corresponding value for stoichimetric hydroxyapatite, $a=$ $9.418 \AA$. Generally, the a-axis length decreased with the synthesis temperature, except for HAP500 which showed the smallest value. Crystallinity of the hydroxyapatites, measured by X-ray diffraction peak broadening as full width at the half-maximum value (FWHM), increased with the synthesis temperature, although HAP500 showed a decrease. These results suggest that the synthetic hydroxyapatites contained some carbonate ions, probably at the A-site of the apatite structure, and that the structure was depleted of carbonate ions at about $500^{\circ} \mathrm{C}$.
\end{abstract}

\section{Introduction}

Hydroxyapatite has been studied extensively and its potential applicability in various fields including use as a fertilizer, chemical catalyst, chromatographic absorbent, ion exchanger and ceramic material has been investigated. These applications have now been extended to the biomineral and medical material sciences $^{[1]}$. Hydroxyapatite as an implant material is attracting growing interest due to its affinity for living tissue and cells. However, basic and clinical data on hydroxyapatite used for implantation are both complex and conflicting. Furthermore, since comparison of different laboratory studies is not easy, mainly because of variability of the chemical and crystal structures of the hydroxyapatites used, there is a danger of misinterpreting the results ${ }^{[2,3,4]}$. Hydroxyapatite shows variable chemical stoichiometry and crystal structure according to the conditions used in its

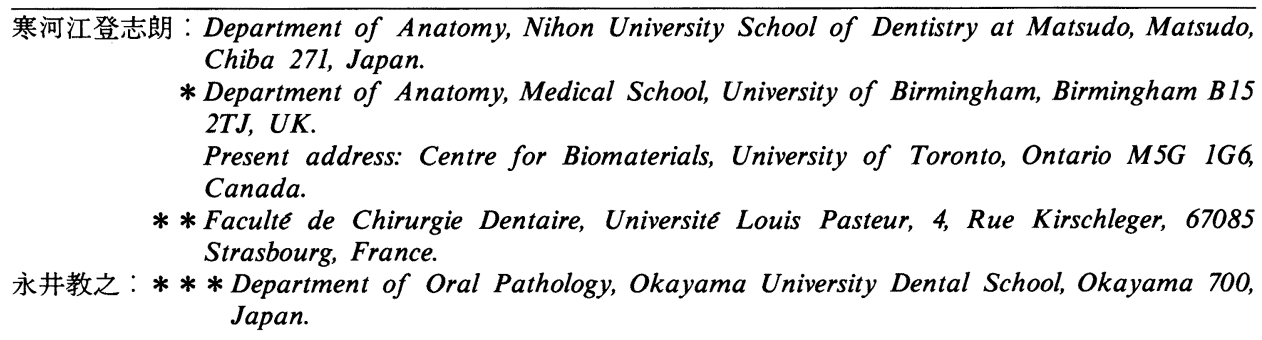
Chiba 271, Japan.

* Department of Anatomy, Medical School, University of Birmingham, Birmingham B15 2TJ, UK.

Present address: Centre for Biomaterials, University of Toronto, Ontario M5G 1G6, Canada.

* * Faculte de Chirurgie Dentaire, Universite Louis Pasteur, 4, Rue Kirschleger, 67085 Strasbourg, France.

永井教之：***Department of Oral Pathology, Okayama University Dental School, Okayama 700, Japan. 
synthesis $^{[6]}$. It is therefore necessary to clearly specify the physico-chemical or crystallographic properties of each hydroxyapatite used in implant studies. The aim of the present study was to describe the crystallographic properties of a series of synthetic hydroxyapatites intended for use in experiments on in vitro implantation.

\section{Materials and Methods}

The hydroxyapatite used as the basis for this series was synthesized by a wet method (Taihei Kagaku Sangyo Co. Ltd., Osaka). After mixing 101 of $1 \mathrm{M} \mathrm{Ca}$ $(\mathrm{OH})_{2}$ and 61 of $1 \mathrm{M} \mathrm{H}_{3} \mathrm{PO}_{4}$ solutions at $80^{\circ} \mathrm{C}$, the filtrate was dried at $200^{\circ} \mathrm{C}$, and pulverized. This material was designated HAP200. Chemical analysis of the material showed that it consisted of $53.60 \mathrm{wt} \% \mathrm{CaO}, 40.59 \mathrm{wt} \% \mathrm{P}_{2} \mathrm{O}_{7}$ and $5.70 \mathrm{wt} \%$ $\mathrm{H}_{2} \mathrm{O}(+)$. After heating of this material at temperatures of $500^{\circ} \mathrm{C}, 900^{\circ} \mathrm{C}$ and $1250^{\circ}$ $\mathrm{C}$, a series of synthetic hydroxyapatites was obtained and were designated HAP 500, HAP900 and HAP1250, respectively.

$\mathrm{X}$-ray powder diffraction studies were then carried out using a Rigaku X-ray Diffractometer under the following conditions: target, $\mathrm{Cu}$; filter, $\mathrm{Ni}$; X-ray wavelength, $1.5418 \AA$; slit system, 1-0.3-1; tube voltage, $40 \mathrm{kV}$; tube current, $20 \mathrm{~mA}$; counting rate, $1000 \mathrm{cps}$; scan speed, $1^{\circ} / \mathrm{min}(2 \theta)$; time constant, 2 ; step interval for computer recording, $0.0167^{\circ}$. Peak broadening was measured on the computerrecorded X-ray diffraction pattern as the full width at half of the peak maximum value (FWHM). Unit cell dimensions of the hydroxyapatite were calculated using a least squares method.

\section{Results}

Figure 1 shows the X-ray diffraction patterns of the synthetic hydroxyapatites in this series. Well resolved peaks were demonstrated in the range $31^{\circ}$ to $33^{\circ}(2 \theta)$ and sharper peaks were also seen in the patterns of the hydroxyapatites heated at high temperature. Crystalline phases other than apatite were not detected.

Figure 2 shows plots of the FWHM values for the apatite (002), (300) and (202) peaks of the synthetic hydroxyapatites. The values decreased with the sample heating temperature except for those of HAP500.

The unit cell dimensions of the synthetic hydroxyapatites, calculated by a least squares method, are listed in Table 1. Figure 3 shows plots of the values of a-axis length for the synthetic hydroxyapatites. Again, the values decreased with the sample heating temperature except for that of HAP500. All a-axis values were smaller than that for stoichiometric hydroxyapatite, $9.4182 \AA^{[5]}$. 


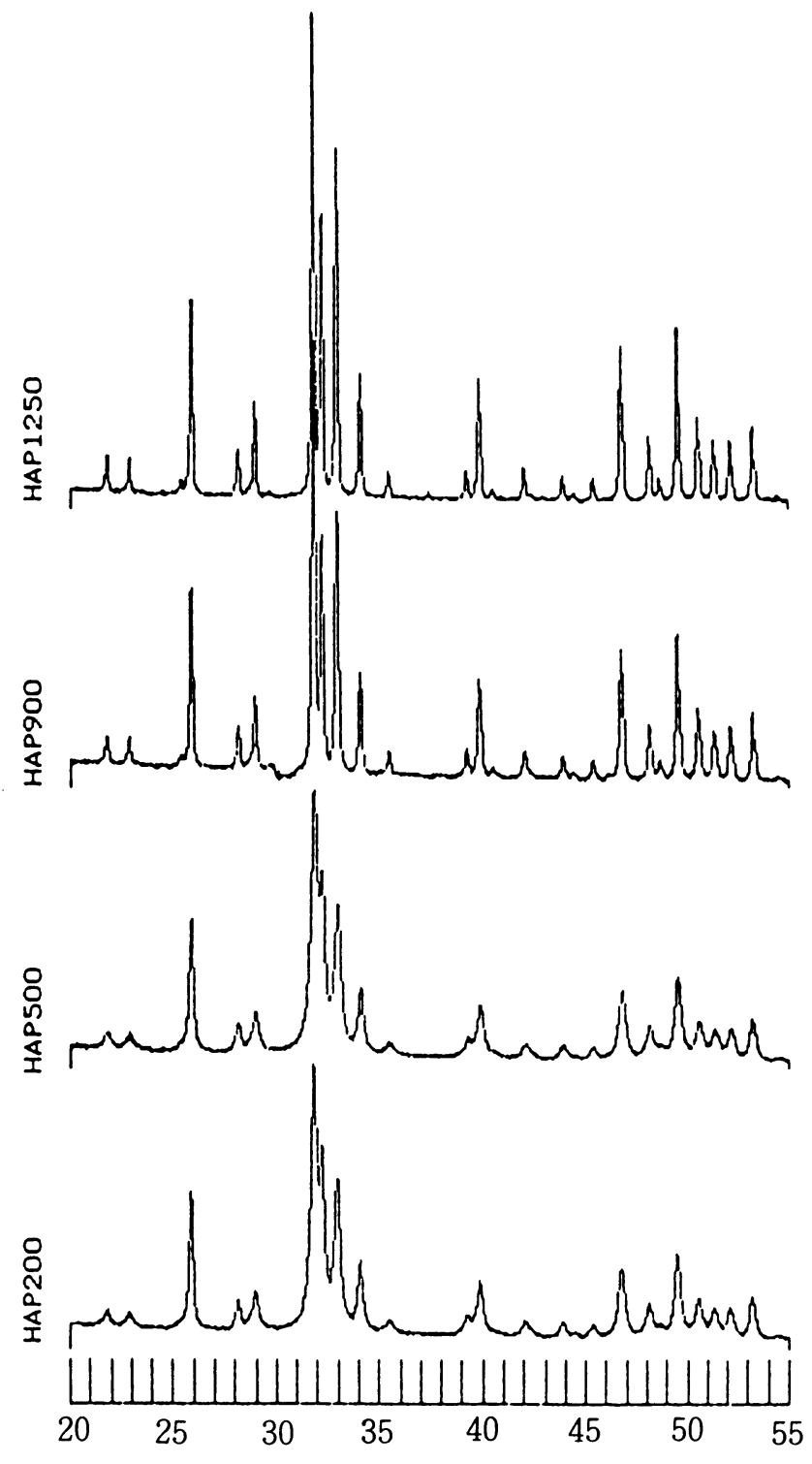

Fig. 1 X-ray diffraction patterns of the synthetic hydroxyapatites 


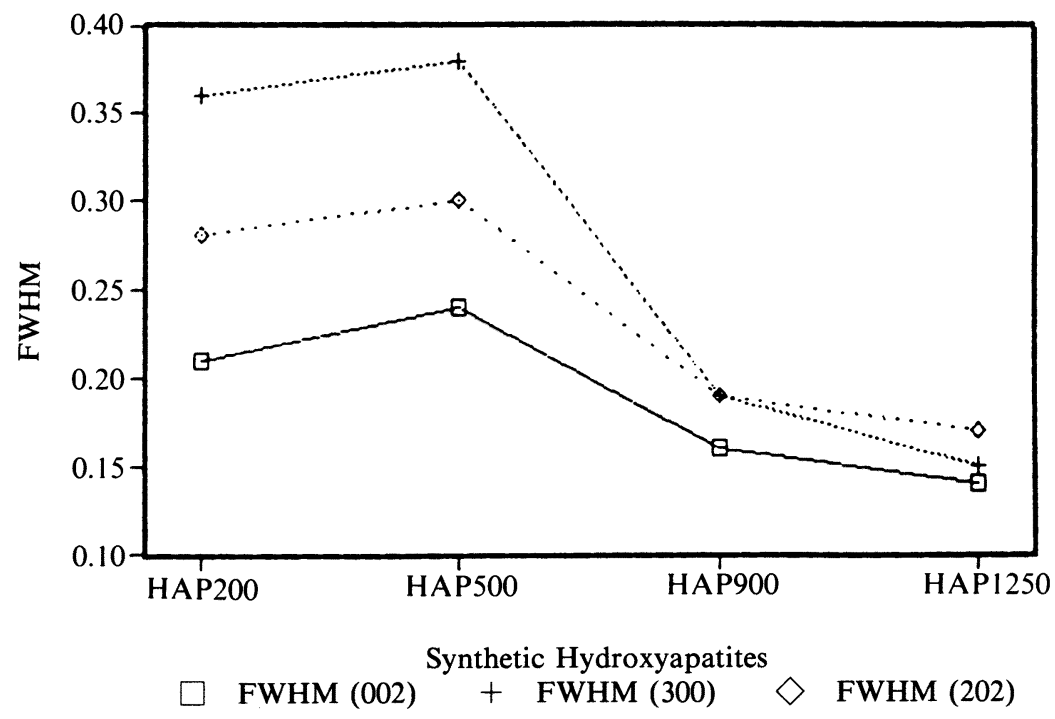

Fig. 2 Peak broadening of the synthetic hydroxyapatites

Table 1 Unit cell dimensions and FWHM values of the synthetic hydroxyapatites

\begin{tabular}{lccccc}
\hline \hline Sample & $\begin{array}{c}\text { a-axis } \\
\text { length } \\
(\mathrm{A})\end{array}$ & $\begin{array}{c}\text { c-axis } \\
\text { length } \\
(\mathrm{A})\end{array}$ & $\begin{array}{c}\text { FWHM } \\
(002)\end{array}$ & $\begin{array}{c}\text { FWHM } \\
(300)\end{array}$ & $\begin{array}{c}\text { FWHM } \\
(202)\end{array}$ \\
\hline HAP200 & 9.416 & 6.886 & 0.21 & 0.36 & 0.28 \\
HAP500 & 9.406 & 6.880 & 0.24 & 0.38 & 0.30 \\
HAP900 & 9.414 & 6.879 & 0.16 & 0.19 & 0.23 \\
HAP1250 & 9.412 & 6.882 & 0.14 & 0.15 & 0.17 \\
\hline
\end{tabular}




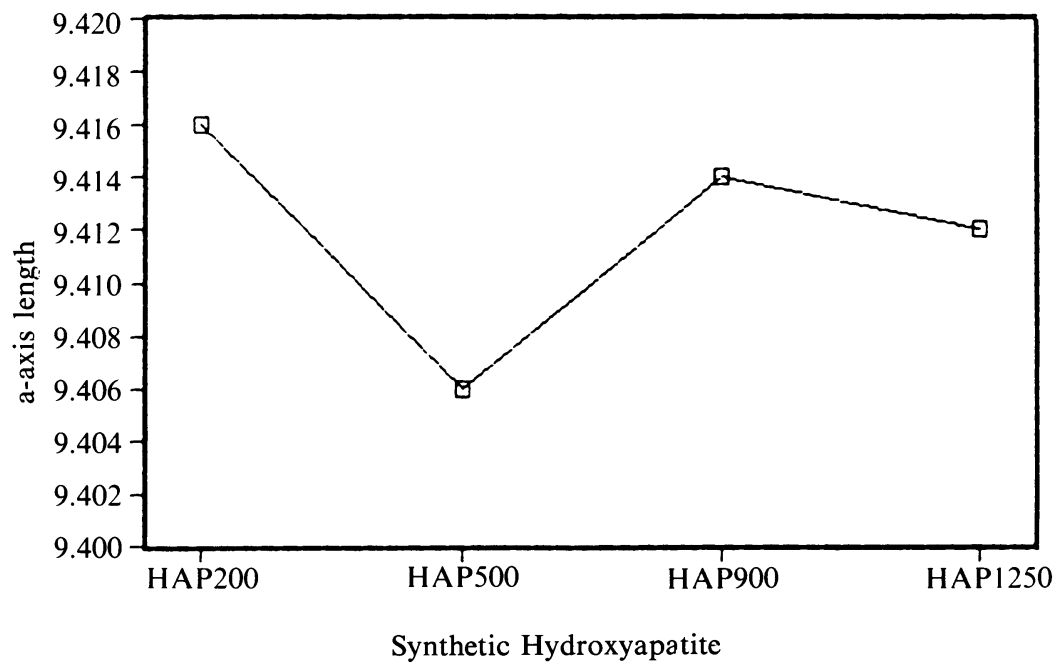

Fig. 3 a-axis length of the synthetic hydroxyapatites

\section{Discussion}

The X-ray diffraction patterns of this series of synthetic hydroxyapatites showed sharpening of the apatite peaks with increased sample heating temperatures. This indicated that the apatite crystals prepared at low temperatures had some structural deficiencies such as lattice defects. However, when compared with tooth enamel crystals, which change to whitlockite upon heating at high temperatures $^{[6]}$, the fact that these synthetic crystals consisted solely of apatite after heating to $1250^{\circ} \mathrm{C}$ suggests that the starting hydroxyapatite was chemically stoichiometric and contained no other impurity.

The FWHM and a-axis length plots of HAP500 were of special interest. The increase of the FWHM value for HAP500 indicated an increase of lattice defects. However, the decrease of a-axis length for HAP500 suggested loss of the A-site carbonate ions in the apatite structure, because carbonate ions at the A-site increase the a-axis length of apatite by $0.026 \AA$ per 1 wt\% ${ }^{[7]}$. Another ion which increases the a-axis length of apatite is "lattice water", which is always found in tooth enamel apatite ${ }^{[7,8]}$. However, this type of $\mathrm{H}_{2} \mathrm{O}$ is unique to tooth enamel apatite and need not be considered in synthetic hydroxyapatite. Therefore, the special features observed for HAP500 indicate loss of carbonate ions from the A-site, causing lattice defects.

This result indicates that even though the chemical components are apparently the same among synthetic hydroxyapatites, their crystallographic properties may differ considerably. 


\section{Acknowledgments}

The authors thank Prof. R. W. Fearnhead of Tsurumi University, Prof. G. Hirai of Nihon University and many of the staff at Université Louis Pasteur for their helpful discussions. Part of this study was funded by a Scientific Foundation Grant from the Science Promotion Association of Japan (to Prof. N. Nagai).

\section{References}

[1] Kanazawa, T., Umegaki, T., Monma, H. and Yamashita, K.: Materials chemistry of apatites, gypsum and lime, 210, 261-273, 1987

[2] Makishima, A. and Aoki, H.: Bioceramics, Giho-Do Shuppan, 43-77, 1984

[3] AoKI, H.and TANBA, Y.: Bioceramics-Development and Clinical Applications. Quintessence, 53-64, 1987

[4] De Groot, K.: Ceramics of calcium phosphates: Preparation and properties. In Bioceramics of Calcium Phosphate, $\mathrm{D}_{\mathrm{E}} \mathrm{G}_{\mathrm{ROOT}}$, K., Ed., CRC Press, Florida, 99-114, 1983

[5] Young, R. A. and Holcomb, D. W.: Variability of hydroxyapatite preparations, Calc. Tiss. Int., 34, S17-S32, 1982

[6] SAKAE, T.: X-ray diffraction and thermal studies of crystals from the outer and inner layers of enamel from human dental enamel, Archs. oral Biol., 33, 707-713, 1988

[7] Young, R. A. and Brown, W. E.: Structures of biological minerals. In Biological Mineralization and Demineralization, Nancollas, G. H., Ed., Springer-Verlag, Berlin, 101-141, 1982

[8] Le Geros, R. Z., Bonel, G. and $\mathrm{L}_{\mathrm{E}}$ Geros, R.: Types of " $\mathrm{H}_{2} \mathrm{O}$ " in human enamel and in prepicitated apatites, Calc. Tiss. Res.,26, 111-118, 1978 